\title{
A Cu(II) POLYMERIC COMPLEX SURVEYING TRIETHANOLAMINE AND 1,2-DI(4-PYRIDYL)ETHYLENE AS BRIDGING LIGANDS
}

\author{
ANA MARÍA ATRIA, ${ }^{1 *}$ JOSÉ PARADA, ${ }^{1}$ MARÍA TERESA GARLAND ${ }^{2}$ AND RICARDO BAGGIO 3 \\ ${ }^{\prime}$ Facultad de Ciencias Químicas y Farmacéuticas, Universidad de Chile, Casilla 233, Santiago, Chile. \\ ${ }^{2}$ Departamento de Física, Facultad de Ciencias Físicas y Matemáticas, Universidad de Chile, Santiago de Chile, Chile. \\ ${ }^{3}$ Departamento de Física, Centro Atómico Constituyentes, Comisión Nacional de Energía Atómica, Buenos Aires, Argentina
}

\begin{abstract}
We report the synthesis and crystal structure of a copper (II) polymeric complex (I) prepared by reaction of $\mathrm{Cu}\left(\mathrm{ClO}_{4}\right)_{2} \cdot 5 \mathrm{H}_{2} \mathrm{O}$ with $\mathrm{H}_{3}$ tea (triethanolamine, and dpe (1,2-di(4-pyridyl)ethylene). in ethanol. The compound is made up of two well differentiated substructures, the first one being a cationic 1D polymer balanced by $\mathrm{ClO}_{4}{ }^{-}$counteranions $\left\{\left[\mathrm{Cu}_{2}\left(\mathrm{H}_{2} \text { tea }\right)_{2}(\mathrm{dpe})\right] \cdot\left(\mathrm{ClO}_{4}\right)_{2}\right\}_{n}$ and the second one made is up of two dimers of different occupancies and charge content, viz., $\left[\mathrm{Cu}_{2}(\mathrm{Htea})_{2}(\mathrm{dpe})\right]^{4}$ (neutral, 64\% occupancy) and $\left[\mathrm{Cu}_{2}\left(\mathrm{H}_{2} \text { tea) }{ }_{2}(\mathrm{dpe})\right]^{2+}\right.$ (cationic, 36\% occupancy), this latter fraction balancing the charge introduced by $\mathrm{ClO}_{4}{ }^{-}$ anions with $72 \%$ occupancy.

Both substructures differ in that the $\mathrm{H}_{\mathrm{m}}$ tea anions in the dimers $(\mathrm{m}=1,2)$ do not bridge cations as their homologue $\mathrm{H}_{2}$ tea does in the polymer, but chelate instead one single $\mathrm{Cu}$ each. As shown in scheme.

The structure of (I) is compared with its close relative $\left[\mathrm{Cu}_{2}\left(\mathrm{H}_{2} \text { tea }\right)_{2}(\mathrm{dpe})\right] \cdot(\mathrm{bpe}) \cdot\left(\mathrm{ClO}_{4}\right)_{2} \cdot \mathrm{H}_{2} \mathrm{O}(\mathrm{II})$, where the same original constituents assemble in a slightly different way ${ }^{1}$.
\end{abstract}

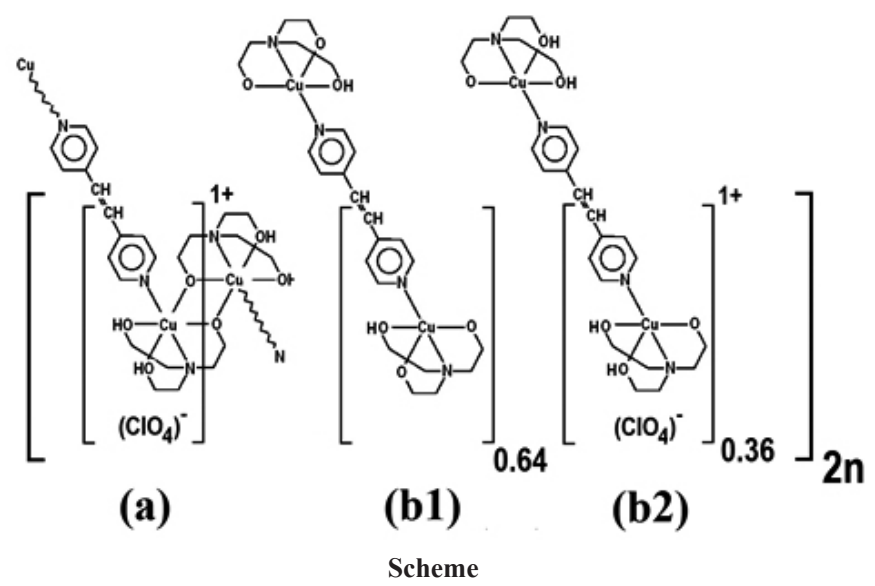

\section{INTRODUCTION}

When looking for the generation of coordination networks (viz., coordination compounds extending in 1,2 or 3 dimensions), the so-called "node and spacer" approach is often preferred. In its simplest description it consists on metal ions, or conglomerates (the nodes) linked by bridging ligands (the spacers) into 1,2 or $3 \mathrm{D}$ arrays $\mathrm{s}^{2,3}$.

The final dimensionality of the crystal structure depends on a number of factors such as reaction conditions, solvent system, counterions, ligand to metal ratio. It is known that 1:1 Ratio often favours 1D structures, larger ratios generally giving rise to larger dimensionalities ${ }^{4-9}$. But not only covalence is relevant to these constructions: the bridging action of non-covalent interactions as hydrogen bonds or $\pi \cdots \pi$ stacking can alter the final results, even in structures with extremely similar constituents. This fact strongly depends in the interplay of H-bonding donor/acceptor eagerness of the species involved.

Two ligands which satisfy these conditions are 1,2-di(4-pyridyl) ethylene (dpe) and trietanolamine ( $\mathrm{H}_{3}$ tea). The first one is a rigid ligand with good bridging capabilities; we have already described some lanthanide and cobalt (II) complexes displaying 1,2-di(4-pyridyl)ethylene bridges ${ }^{10,11}$. Triethanolamine, in turn, may be considered as a flexible ligand which can act with different degrees of protonation and participates in the formation of nodes or conglomerate ${ }^{12}$.

We present herein an example of an unreported Copper (II) complex surveying both ligands,

$\left\{\left[\mathrm{Cu}_{2}\left(\mathrm{H}_{2} \text { tea }\right)_{2}(\mathrm{dpe})\right] \cdot\left(\mathrm{ClO}_{4}\right)_{2}\right\} \mathrm{n} \cdot 0.64 \mathrm{n}\left[\mathrm{Cu}_{2}(\mathrm{Htea})_{2}(\mathrm{dpe})\right] \cdot 0.36 \mathrm{n}\left\{\left[\mathrm{Cu}_{2}\left(\mathrm{H}_{2}\right.\right.\right.$ tea )$\left.\left._{2}(\mathrm{dpe})\right] \cdot\left(\mathrm{ClO}_{4}\right)_{2}\right\}$.

The compound is strongly related to a close relative $\left[\mathrm{Cu}_{2}\left(\mathrm{H}_{2} \text { tea }\right)_{2}(\mathrm{dpe})\right] \cdot($ bpe) $\cdot\left(\mathrm{ClO}_{4}\right)_{2} \cdot \mathrm{H}_{2} \mathrm{O}$ (II) where the same original constituents ensamble slightly differently, in such a way that H-bonding ends up being crucial in defining the final dimensionality of the supramolecular arrangement of both compounds ${ }^{1}$.

\section{EXPERIMENTAL}

\subsection{Synthesis}

To an aqueous solution $(200 \mathrm{~mL})$ of copper perchlorate pentahydrate $(0.55 \mathrm{mmol}, 0.2037 \mathrm{~g})$ was added a solution of triethanolamine $(0.981 \mathrm{mmol}$, $0.1462 \mathrm{~g}$ ) in $25 \mathrm{~mL}$ of ethanol with constant stirring. The resulting suspension was stirred and heated for $15 \mathrm{~min}$. Then $2,2 \mathrm{mmol}(0.4009 \mathrm{~g})$ of 1, 2-di(4pyridyl)ethylene dissolved in the same solvent $(25 \mathrm{~mL})$ was added and the resulting mixture was refluxed for $4 \mathrm{~h}$ and filtered while hot. The filtrate was left at room temperature. On standing, single crystals suitable for X-ray analysis were obtained, which were used without further processing.

\subsection{X-Ray crystallography}

The diffractometer data set was collected up to a $2 \theta$ max of ca. $58^{\circ}$ using monochromatic Mo Ka radiation, $\alpha=0.7107 \AA$, $T=295 \mathrm{~K}$ on a Bruker Smart diffractometer. The following software was used in different stages of the crystal structure analysis process: Data collection: CrysAlis PRO (Oxford Diffraction, $2009)^{13}$ program(s) used to solve structure: SHELXS97; program(s) used to refine structure: SHELXL97; molecular graphics: SHELXTL ${ }^{14}$

\subsection{Refinement}

The structure showed disorder around both perchlorate anions (PCA), viz., PCA\#1, split into two rotationally disordered halves around a unique C11O41 bond (occupation factors: 0.637, 0.363 (4)) and PAC\#2 with C12 sitting on an inversion centre and showing, in addition to the concomitant disorder, incomplete occupation. Steric hindrance between the major component of PCA\#1 and the PCA\#2 unit, forced the depleted occupation of the latter to be equal to that of the minor component of PCA\#1 ( 0.363 (4) ). Charge balance required that the negative charge introduced by this latter fraction ought to be balanced by an equivalent positive charge from the $\mathrm{H}_{\mathrm{m}}$ tea groups in the dimeric 
moieties. Even if the trustable finding of the corresponding hydrogens proved illusory, due to the prevailing disorder, there is in the structure strong evidence of their whereabouts: when the set of short $\mathrm{O} \cdots \mathrm{O}$ contacts in the structure is analyzed, it is found that all of them could be satisfactory explained by $\mathrm{H}$-bonds from the $\mathrm{H}_{2}$ tea groups in the polymeric subunit, except $\mathrm{O} 13 \cdots \mathrm{O} 12=2.560$ (6) and $\mathrm{O} 33 \cdots \mathrm{O} 12^{\mathrm{ii}}=2.660(6)$, (ii) $=-\mathrm{x}+1,-\mathrm{y}+2,-\mathrm{z}+1$. This fact strongly suggests the presence of unnoticed, disordered H's attached to O13 and O33 in the remaining subunit, thus giving support to the proposed formulation.

\subsection{Physical measurements.}

The UV-Vis spectrum was recorded with $1.0 \mathrm{~cm}$ quartz cells on a UNICAM UV3 spectrophotometer in the DMSO solution at room temperature.

\section{RESULTS AND DISCUSSION}

Crystal data, data collection and structure refinement details are summarized in Table 1, while Table 2 presents coordination distances and Table 3 the most relevant H-bonding interactions. The compound consists of two well differentiated 2:2:1 Cu- $\mathrm{H}_{\mathrm{m}}$ tea-dpe substructures, $\mathrm{m}=1,2$ (Fig.1, (a) and (b) ) completed by perchlorate anions as solvates.

(a)

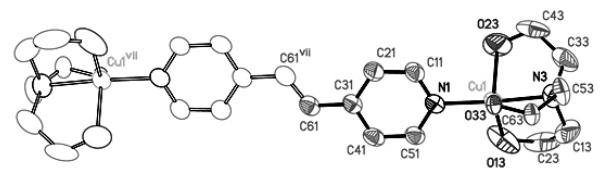

(b)

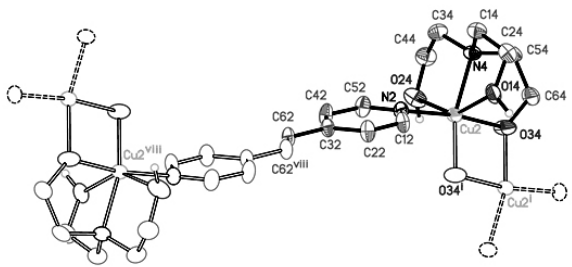

Figure 1: Ellipsoid plots (drawn at a 30\% probability level) of the three components in the structure. In full ellipsoids, the independent part. $\mathrm{H}$ atoms attached to $\mathrm{C}$ not shown. (a) The centrosymmetric dimeric spacers built up around $\mathrm{Cu} 1$. (b) The centrosymmetric elemental brick for the $\mathrm{Cu} 2$ chains. Symmetry codes: (i) $-x+1,-y+1,-z$; (vii) $-x+1,-y+1,-z+1$; (viii) $-x+2,-y+1$, $-z+1$.

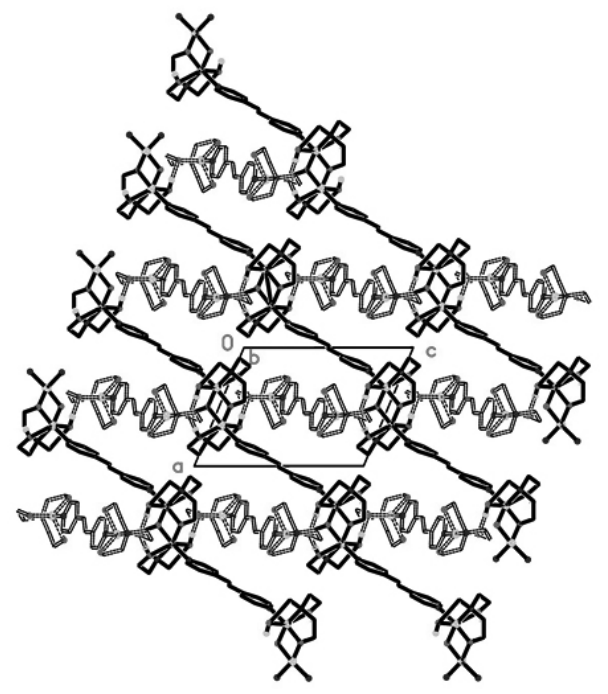

Figure 2: A projection of the structure along [010], showing in full lining the chains parallel to (Fig1 (b)), and in double broken lines, the spacers linking them (Fig 1 (a)) into the (010) undulating planes.
The substructure (b) associated to Cu1 consists of two types of dimers appearing in a disordered fashion, almost identical in structure but with a different charge content, viz., (b1), formulated as $\left[\mathrm{Cu}_{2}(\mathrm{Htea})_{2}(\mathrm{dpe})\right]$ and (b2), as $\left[\mathrm{Cu}_{2}\left(\mathrm{H}_{2} \text { tea }\right)_{2}(\mathrm{dpe})\right]^{2+}$, in a $0.64: 0.36$ ratio.

Table 1: Experimental details.

Crystal data

\begin{tabular}{|c|c|}
\hline Chemical formula & $\begin{array}{c}2\left(\mathrm{C}_{12} \mathrm{H}_{19} \mathrm{CuN}_{2} \mathrm{O}_{3} \cdot\right. \\
\left.\mathrm{ClO}_{4}\right] \cdot 1.28\left[\mathrm{C}_{12} \mathrm{H}_{18} \mathrm{CuN}_{2} \mathrm{O}_{3}\right] . \\
\left.0.72\left[\mathrm{C}_{12} \mathrm{H}_{19} \mathrm{CuN}_{2} \mathrm{O}_{3} \cdot \mathrm{ClO}_{4}\right)\right]\end{array}$ \\
\hline$M_{\mathrm{r}}$ & 1479.09 \\
\hline Crystal system, space group & Triclinic, $P^{-} 1$ \\
\hline Temperature $(\mathrm{K})$ & 294 \\
\hline$a, b, c(\AA)$ & $10.504(3), 12.935(3), 13.685(3)$ \\
\hline$\alpha, \beta, \gamma\left(^{\circ}\right)$ & $106.951(5), 104.640(4), 109.350(5)$ \\
\hline$V\left(\AA^{3}\right)$ & $1547.4(6)$ \\
\hline$Z$ & 1 \\
\hline Radiation type & Mo $K \alpha$ \\
\hline$\mu\left(\mathrm{mm}^{-1}\right)$ & 1.555 \\
\hline Crystal size (mm) & $0.41 \times 0.31 \times 0.15$ \\
\hline \multicolumn{2}{|c|}{ Data collection } \\
\hline Diffractometer & $\begin{array}{l}\text { Bruker SMART CCD area detector } \\
\text { diffractometer }\end{array}$ \\
\hline Absorption correction & $\begin{array}{c}\text { Multi-scan } \\
\text { SADABS in SAINT-NT (Bruker, } \\
\text { 2002) }\end{array}$ \\
\hline$T_{\min }, T_{\max }$ & $0.58,0.82$ \\
\hline $\begin{array}{c}\text { No. of measured, independent and } \\
\text { observed }[I>2 \sigma(I)] \text { reflections }\end{array}$ & $12834,6592,5181$ \\
\hline$R_{\text {int }}$ & 0.014 \\
\hline$(\sin \theta / \lambda)_{\max }\left(\AA^{-1}\right)$ & 0.659 \\
\hline \multicolumn{2}{|c|}{ Refinement } \\
\hline$R\left[F^{2}>2 \sigma\left(F^{2}\right)\right], w R\left(F^{2}\right), S$ & $0.057,0.162,1.02$ \\
\hline No. of reflections & 6592 \\
\hline No. of parameters & 451 \\
\hline No. of restraints & 147 \\
\hline $\mathrm{H}$-atom treatment & $\begin{array}{l}\mathrm{H} \text { atoms treated by a mixture } \\
\text { of independent and constrained } \\
\text { refinement }\end{array}$ \\
\hline$\Delta>_{\max }, \Delta>_{\min }\left(\mathrm{e} \AA^{-3}\right)$ & $0.62,-0.94$ \\
\hline
\end{tabular}

The dimers are centrosymmetric and are made up of a dpe molecule halved by an inversion centre at the central $\mathrm{C}=\mathrm{C}$ bond, bound to two symmetry related $\mathrm{Cu}$ (II) cations through the outermost N's in a bridging mode. The $\mathrm{Cu}(\mathrm{II})$ cations, in turn, are further chelated by partially deprotonated $\mathrm{H}_{\mathrm{m}}$ tea anions (either Htea in (b1) or $\mathrm{H}_{2}$ tea in (b2); see discussion about charge balance at the end of the discussion), binding in $\mathrm{k}^{4}-\mathrm{N}, \mathrm{O}, \mathrm{O}$ ', O' mode. Cul is thus five coordinated, inmersed in a distorted Trigonal Bipyramidal environment (Fig. 1(a), inset), as disclosed by the $\tau$ parameter $(\tau=0.70$. Expected values: 0.00 for and ideal Square pyramid; 1.00 for an ideal Trigonal Bipyramid ${ }^{15}$. The triangular base is defined by the three alkoxo oxygens $(\mathrm{O} 13, \mathrm{O} 23, \mathrm{O} 33)$ with $\mathrm{Cu} 1$ being 0.169 (2) $\AA$ away from the plane, and the amino nitrogen N1 and 
the dpe nitrogen $\mathrm{N} 3$ in apical positions, subtending to the plane normal $\mathrm{N}-\mathrm{Cu}$ angles of $1.5(1)^{\circ}(\mathrm{N} 1-\mathrm{Cu} 1)$ and $3.2(1)^{\circ}(\mathrm{N} 3-\mathrm{Cu} 1)$.

The subunit (a) associated to $\mathrm{Cu} 2$, is instead a 1D polymeric structure bearing only minor differences to the previous one. Here the $\mathrm{H}_{2}$ tea anion acts in a $\mu_{2} \mathrm{k}^{4}-\mathrm{N}, \mathrm{O}, \mathrm{O}$ ', O" mode due to the unprotonated alkoxo oxygen (O34) binding a second copper cation of a neighbouring unit and thus bridging dimers around a second inversion centre and defining a catemer as a result. The effect of the $\mathrm{O} 34$ bridging is the appearance of a rombic $\mathrm{O}-\mathrm{Cu}-\mathrm{O}-\mathrm{Cu}$ loop with a rather short Cu2 $\cdots \mathrm{Cu} 2[1-\mathrm{x},-\mathrm{y},-\mathrm{z}]$ distance of 2.9229 (12) $\AA$. As a consequence of the different coordination of the anion the $\mathrm{Cu} 2$ ion presents a strongly distorted square bipyramidal geometry (Fig. 1(b), inset), with the base defined by N2, $\mathrm{N} 4, \mathrm{O} 34$ and $\mathrm{O} 34$ [1-x,-y,-z] (maximum departure from the L.S. plane: 0.053 (1) $\AA$ for $\mathrm{O} 34$, with $\mathrm{Cu} 2$ being 0.055 (1) $\AA$ away from the plane). The apical sites are occupied by the weakly coordinated $\mathrm{O} 14$ and $\mathrm{O} 24$ from $\mathrm{OH}$ groups, subtending $\mathrm{O}-\mathrm{Cu}$ angles of $13.6(1)^{\circ}(\mathrm{O} 14-\mathrm{Cu} 2)$ and $14.9(1)^{\circ}(\mathrm{O} 24-\mathrm{Cu} 2)$.

Table 2: Selected bond lengths ( $\AA$ ) for (I).

\begin{tabular}{|c|c|c|c|}
\hline $\mathrm{Cu} 1-\mathrm{O} 23$ & $1.926(3)$ & $\mathrm{Cu} 2-\mathrm{O} 34^{\mathrm{i}}$ & $1.910(3)$ \\
\hline $\mathrm{Cu} 1-\mathrm{N} 1$ & $1.981(4)$ & $\mathrm{Cu} 2-\mathrm{O} 34$ & $1.924(3)$ \\
\hline $\mathrm{Cu} 1-\mathrm{O} 13$ & $2.006(5)$ & $\mathrm{Cu} 2-\mathrm{N} 2$ & $2.035(3)$ \\
\hline $\mathrm{Cu} 1-\mathrm{N} 3$ & $2.012(5)$ & $\mathrm{Cu} 2-\mathrm{N} 4$ & $2.062(3)$ \\
\hline $\mathrm{Cu} 1-\mathrm{O} 33$ & $2.155(5)$ & $\mathrm{Cu} 2-\mathrm{Cu} 2{ }^{\mathrm{i}}$ & $2.9222(11)$ \\
\hline
\end{tabular}

Symmetry code: (i) $-x+1,-y+1,-z$.

The crystal structure can be envisaged as a planar (010) layout of $\mathrm{Cu} 2$ chains running along [101] with interspersed Cul dimeric units acting as connectors (Fig. 2). Two strong H-bonding interactions (Table 3, \#1,\#2) serve to this end, linking the 1D structures through the dimeric spacers to define ondulating 2D structures parallel to (010) (Fig. 3).

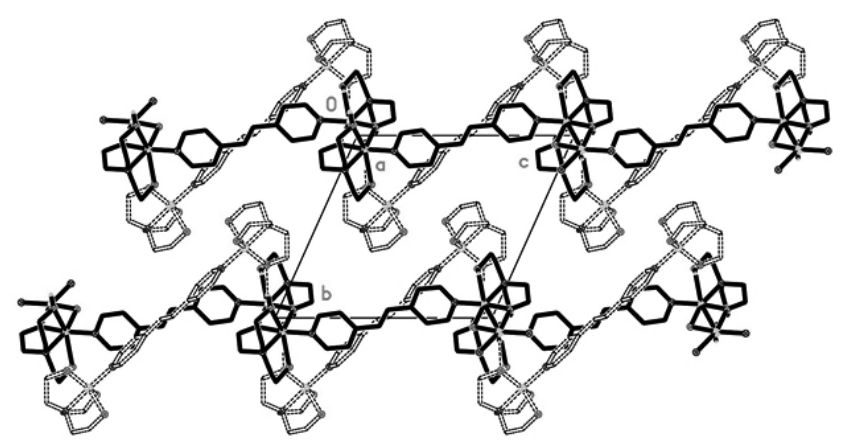

Figure 3: A projection of the structure along [100], showing sideways the planes presented in Fig. 2.

There are in addition two weaker, rather unusual $\pi$ interactions complementing this linkage: a $\mathrm{C}-\mathrm{H}-\pi$ one involving the $\mathrm{C} 62=\mathrm{C} 62$ ' double bond (Table $3, \# 3$ ) and a T-shaped $\pi-\pi$ one (Table 4 ).

Fig.4a shows a projection down [001] where columnar voids along c can be clearly seen. This is precisely the locus of the perchlorate anions (Fig.4b) which dispose in these unoccupied regions, with weak interactions between themselves (Table 3, \#4) and to the main frame (Table 3, \#5 to \#16) It is interesting to compare (I) with its related structure $\left[\mathrm{Cu}_{2}\left(\mathrm{H}_{2} \text { tea }\right)_{2}(\mathrm{dpe})\right] \cdot 2 \cdot\left(\mathrm{ClO}_{4}\right)_{\mathrm{n}} \mathrm{H}_{2} \mathrm{O}$ (II), which is built up of exactly the same cationic $1 \mathrm{D}$ chains, but where the dimeric units in (I) are replaced by simple dpe spacers ${ }^{1}$. Charge balance is therein achieved by the presence of ordered perchlorate anions instead of the disordered ones in (I). These compositional differences introduce in turn differences in the H-bonding scheme, which end up reflecting in the packing dimensionality. Both structures share the same elemental "brick" in the chain, with four H's, viz., those from the two "terminal" $\mathrm{H}_{2}$ tea anions, centrosymmetrically related in I ( but independent in II) available for strong linkage. However, while in I all four are used in interchain connections with the result of the 2D structure already discussed, in II two of these H-bonds are lost for this latter purpose, one of them being intramolecular (to one vicinal oxo $\mathrm{O}$ ) and a second ends up being received by a strong pendant chlorate acceptor. Under these conditions only two chains can be linked into a 1D strip, as shown in Fig. 4. Thus, the final dimensionality is defined by the different strength and capabilities of the H-bonding acceptors in both structures, viz., stronger deprotonated oxo O's in I vs weaker pyridyl N's in II.

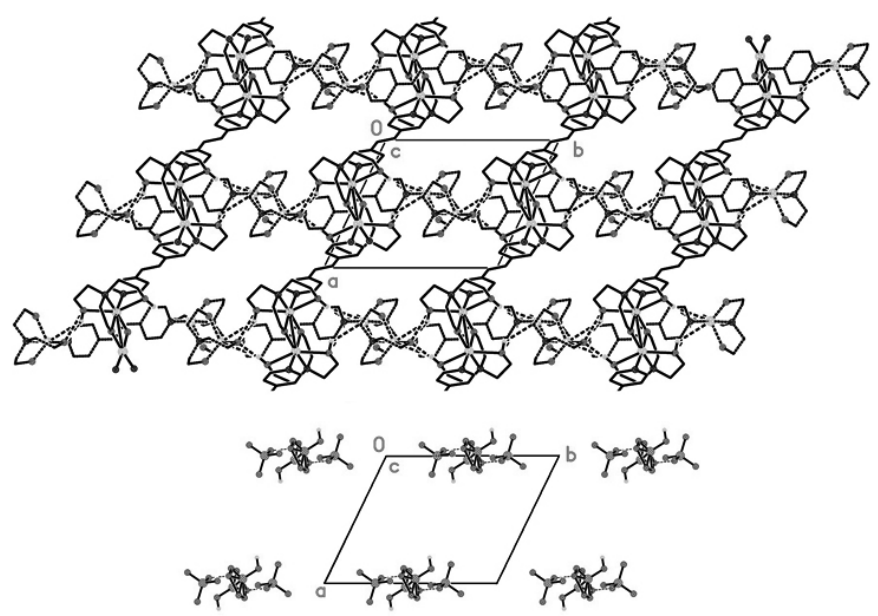

Figure 4: (a) Another sideways view of the 1D substructures, now projected down [001] and showing the columnar voids left between the 1D arrays. (b) The columnar disposition of the perchlorate anions, filling the voids shown above.

Table 3: Hydrogen-bond geometry $\left(\AA,^{\circ}\right)$ for (I).

\begin{tabular}{|c|c|c|c|c|}
\hline$D-\mathrm{H} \cdots A$ & $D-\mathrm{H}$ & $\mathrm{H} \cdots A$ & $D \cdots A$ & $D-\mathrm{H} \cdots A$ \\
\hline $\mathrm{C} 11-\mathrm{H} 11 A \cdots \mathrm{O} 42 A^{\text {ii }}$ & 0.93 & 2.37 & $3.188(10)$ & 146 \\
\hline $\mathrm{C} 12-\mathrm{H} 12 A \cdots \mathrm{O} 14$ & 0.93 & 2.35 & $3.016(5)$ & 128 \\
\hline $\mathrm{C} 22-\mathrm{H} 22 A \cdots \mathrm{O} 31 A^{\mathrm{iii}}$ & 0.93 & 2.50 & $3.375(9)$ & 157 \\
\hline $\mathrm{C} 22-\mathrm{H} 22 A \cdots \mathrm{O} 11 B^{\mathrm{iii}}$ & 0.93 & 2.34 & $3.092(12)$ & 137 \\
\hline $\mathrm{C} 42-\mathrm{H} 42 A \cdots \mathrm{O} 32 A^{\mathrm{iv}}$ & 0.93 & 2.50 & $3.284(15)$ & 142 \\
\hline $\mathrm{C} 52-\mathrm{H} 52 A \cdots \mathrm{O} 24$ & 0.93 & 2.43 & $3.098(5)$ & 129 \\
\hline $\mathrm{C} 52-\mathrm{H} 52 A \cdots \mathrm{O} 22 A^{\mathrm{iv}}$ & 0.93 & 2.54 & $3.391(16)$ & 152 \\
\hline $\mathrm{C} 52-\mathrm{H} 52 A \cdots \mathrm{O} 42 A^{\mathrm{ii}}$ & 0.93 & 2.27 & $2.996(14)$ & 135 \\
\hline $\mathrm{C} 23-\mathrm{H} 23 B \cdots \mathrm{O} 32 A$ & 0.97 & 2.57 & $3.179(14)$ & 121 \\
\hline $\mathrm{C} 63-\mathrm{H} 63 A \cdots \mathrm{O} 31 B^{\mathrm{ii}}$ & 0.97 & 2.43 & $3.197(13)$ & 136 \\
\hline $\mathrm{C} 14-\mathrm{H} 14 B \cdots \mathrm{O} 11 B^{\mathrm{v}}$ & 0.97 & 2.44 & $3.225(12)$ & 138 \\
\hline $\mathrm{C} 44-\mathrm{H} 44 A \cdots \mathrm{O} 22 A^{\mathrm{iv}}$ & 0.97 & 2.48 & $3.133(10)$ & 124 \\
\hline $\mathrm{C} 54-\mathrm{H} 54 B \cdots \mathrm{O} 11 A^{\mathrm{v}}$ & 0.97 & 2.57 & $3.515(8)$ & 166 \\
\hline $\mathrm{O} 14-\mathrm{H} 14 \cdots \mathrm{O} 23^{\mathrm{i}}$ & $0.85(1)$ & $1.87(2)$ & $2.688(4)$ & $163(4)$ \\
\hline $\mathrm{O} 24-\mathrm{H} 24 \cdots \mathrm{O} 23$ & $0.85(1)$ & $1.91(3)$ & $2.693(5)$ & $154(5)$ \\
\hline
\end{tabular}

Symmetry codes: (i) $-x+1,-y+1,-z$; (ii) $x+1, y, z$; (iii) $x+1, y-1, z$; (iv) $-x+1,-y+2,-z+1 ;(\mathrm{v})-x+1,-y+2,-z$.

Since some of the $\mathrm{H}$ atoms could not be trustable found, a discussion regarding the way in which charge balance has been justified is in force.

To begin with, if the depleted perchlorate anion were not present the formula of (I) could be written, for the sake of clarity, as a two member sum of two substructures, viz., a polymeric one (a) $\left.\left\{\left[\mathrm{Cu}_{2}\left(\mathrm{H}_{2} \text { tea }\right)_{2}(\mathrm{dpe})\right] \cdot 2 \mathrm{ClO}_{4}\right)\right\}_{\mathrm{n}}$ and a dimeric one (b) $\left[\mathrm{Cu}_{2} \text { (Htea) }\right)_{2}$ dpe)], both neutral from a charge density point of view, where $\mathrm{H}_{2}$ tea and Htea stand for tea groups with one or two alkoxo groups lacking their respective $\mathrm{H}$ atoms.

The existence of the extra perchlorate charge $(-0.72 \mathrm{e})$ means there must be some extra positive charge balancing it, coming from $\mathrm{H}_{\mathrm{m}}$ tea anions presenting an average negative charge smaller than so far described.

On one side the triethanolamine group bound to $\mathrm{Cu} 2$, (atoms defined by their training label 4) presents its two H's quite ordered and making clear, strong H-bonds, for what they could be ruled out for this purpose. The logical 
candidate in the triethanolamine group 3, bound to $\mathrm{Cu} 1$ in the dimeric units, which ought to present a disordered protonation state in the form of Htea $(\mathrm{m}=1)$ and $\mathrm{H}_{2}$ tea $(\mathrm{m}=2)$ in a $0.64: 0.36$ ratio. With this formulation, the dimeric group (b2) would be a cation providing a formal charge of +0.72 , thus balancing the $0.72\left(\mathrm{ClO}_{4}^{-}\right)$depleted counterion.

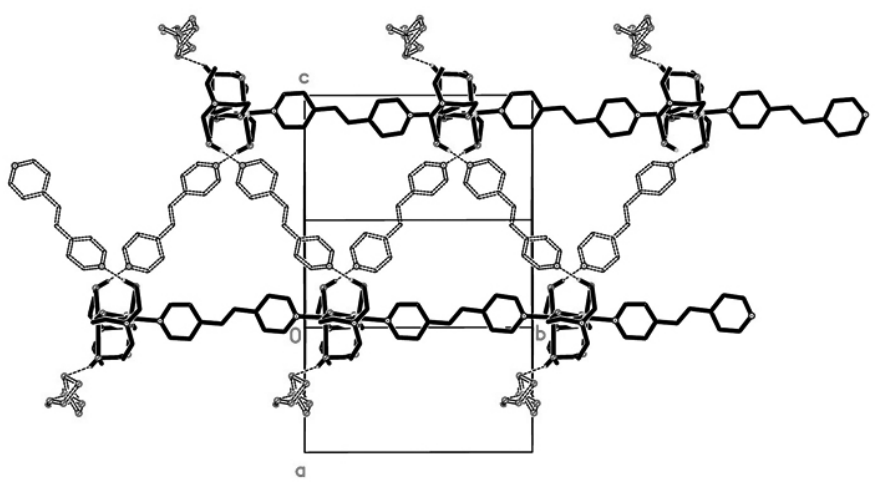

Figure 5: A view of the 1D strips built up in structure II, to be compared with the 2D structure in $\mathbf{I}$, shown in Fig 2. Note the H-bonds ending up in perchlorate anions, interrupting the 2D H-bonding sequence.

The UV-vis spectrum of (I) has been measured. It shows a band at 302 $\mathrm{nm}$ and a shoulder at $318 \mathrm{~nm}$ which can be ascribed to the $\pi \cdots \pi$ interaction between ligands and to a charge transfer transition, respectively. The broad band centered at $748 \mathrm{~nm}$ in the visible region is assignable to a d-d transition of the copper ion ${ }^{16}$.

\section{CONCLUSION}

In summary, a new copper (II) complex with (1,2-di(4-pyridyl)ethylene) and triethanolamine as bridging ligands was synthesized and characterized by X-ray diffraction. The structure shows an interesting behavior of the intervening ligands: while the former one fulfills its usual, well documented spacer role, the triethanolamine counterpart exhibits instead different degrees of deprotonation and coordination modes, a fact which in turn gives raise to well differentiated substructures. The fact that most of them are cationic introduces the need for charge balance, in turn achieved by a large, non-integer number of free perchlorate counterions. This fact introduces an extremely large number of $\mathrm{H}$-bonding donors and acceptors in the structure, which leads to a very complex intermolecular interaction scheme, partially responsible of the final crystal cohesion.

\section{Supplementary material}

Crystallographic data for the structural analysis have been deposited with the Cambridge Crystallographic Data Centre, CCDC No 1054040.

\section{ACKNOWLEDGEMENTS}

This work was supported by FONDECYT project 1120125 .

\section{REFERENCES}

1) V. Tudor, G. Marin, V. Kravtsov, Y.A.Simonov, J. Lipkowski, M. Brezeanu, M. Andruh. Inorg. Chim. Acta 353, 35, (2003).

2) H.K. Liu, X. H. Huang, T.G. Lu, X.J. Wang, W.Y. Sun, B.S. Kang. Dalton Trans. 3178, (2008).

3) W.L. Meng, J. Fan, T.-A. Okamura, H. Kawaguchic, Y. Lv, W.Y. Sun, N Ueyama, Z. Anorg. Allg. Chem. 632, 1890, (2006).

4) M. Andruh, H.W. Roesky, M. Noltemeyer, H-G. Schmidt, Z. Naturforsch $B, \mathbf{4 9}, 31,(1994)$.

5) J. Lu, C. Yu, T. Niu, T. Paliwala, G. Crisci, F. Somosa, A. J. Jacobson, Inorg. Chem. 37, 4637, (1998).

6) Yue Wang, Yan Qi , Qun Li, Zhou Lv, Yanwei Wang. Polyhedron. 85, $389,(2015)$.

7) F. Luo, Y.X. Che, J. M. Zheng, Cryst. Growth. Des. 9, 1066, (2009).

8) R. Sarma, D. Kalita, J. B. Baruah, Dalton Trans. 7428, (2009).

9) Z. W. Wang, C.C. Ji, J.Li, Z.J. Guo, Y.Z. Li, H. G. Zheng, Cryst. Growth Des. 9, 475, (2009).
10) J. C. Muñoz, A. M. Atria, R. Baggio, M. T. Garland, O. Peña, C.Orrego, Inorg. Chim. Acta, 358, 4027, (2005).

11) A.M.Atria, G.Corsini, A.Talamilla, M.T.Garland, R. Baggio. Acta Cryst. C65, 24, (2009).

12) Ana-Maria-Corina Dumitriu, Maria Cazacu, Alexandra Bargan, Sergiu Shova, Constantin Turta. Polyhedron, 50, 255, (2013)

13) Oxford Diffraction (2009). Crys Alis CCD and Crys Alis RED. Oxford Diffraction Ltd, Yarnton, Oxfordshire, England

14) Sheldrick, G. M. Acta Cryst. A64, 112, (2008).

15) A. W. Addison, T. N. Rao, J. Reedijk, J. Van Rijn, G. C. Verschoor, J. Chem. Soc. Dalton Trans. 1349, (1984).

16) A. B. P. Lever. Inorganic Electronic Spectroscopy, Elsevier, Amsterdam, 1986. 